\title{
CORRECTION
}

\section{Correction: DNA microarray analysis of rheumatoid arthritis susceptibility genes identified by genome-wide association studies}

\author{
Hidehiko Sugino', Hooi-Ming Lee' and Norihiro Nishimoto*1,2 \\ See related research by Sugino et al., http://arthritis-research.com/content/12/2/401
}

After publication of our recent article [1], we noticed an error in Table 1. Gene expression of STAT4 should be listed as "down" and not "up". The description of the table in the article is unchanged and the corrected table is provided here.

\section{Competing interests}

This study was financially supported partly by the grant from the Ministry of Health, Labor and Welfare of Japan.

\section{Author details}

'Graduate School of Frontier Bioscience, Osaka University, 1-3 Yamada-Oka, Suita-City, Osaka 565-0871, Japan

${ }^{2}$ Laboratory of Immune Regulation, Wakayama Medical University, 105 Saito Bio Innovation Center, 7-7-20 Saito-Asagi, Ibaraki-city Osaka, 567-0085, Japan
Published: 24 May 2010

\section{References}

1. Sugino H, Lee HM, Nishimoto N: DNA microarray of rheumatoid arthritis susceptibility genes identified by genome-wide association studies. Arthritis Research \& Therapy 2010, 12:401.

Table 1. Candidate genes identified from rheumatoid arthritis genome-wide association studies

\begin{tabular}{lcccc}
\hline Gene & GenelD & PMID & Gene expression (up or down) & Microarray $P$ values $^{\mathbf{a}}$ \\
\hline CD244 & 605554 & 18794858 & Up & $1.0 \times 10^{-16}$ \\
PAD14 & 605347 & 12833157 & Up & $2.32 \times 10^{-5}$ \\
SLC22A2 & 602608 & 14608356 & Up & $1.94 \times 10^{-6}$ \\
PTPN22 & 600716 & 15208781 & Up & $9.66 \times 10^{-8}$ \\
CTLA4 & 123890 & 16380915 & No change & 0.767 \\
STAT4 & 600558 & 17804842 & Down & $1.38 \times 10^{-8}$ \\
\hline
\end{tabular}

a $P$ values determined by comparison between 112 rheumatoid arthritis patients and 45 healthy individuals.

*Correspondence: norihiro@fbs.osaka-u.ac.jp

'Graduate School of Frontier Bioscience, Osaka University, 1-3 Yamada-Oka,

Suita-City, Osaka 565-0871, Japan

Full list of author information is available at the end of the article

doi:10.1186/ar3023

Cite this article as: Sugino $H$, et al:: Correction: DNA microarray analysis of rheumatoid arthritis susceptibility genes identified by genome-wide association studies. Arthritis Research \& Therapy 2010, 12:403. 